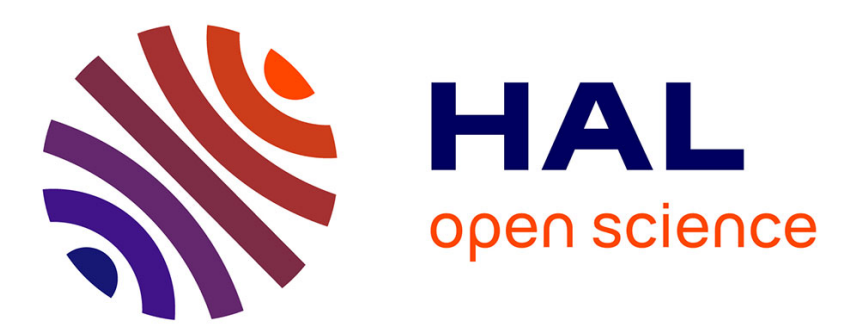

\title{
Research on the Current Situation and Development of Intelligent Precision Fertilizer Technology \\ Wu Yan, Wang Fan
}

\section{To cite this version:}

Wu Yan, Wang Fan. Research on the Current Situation and Development of Intelligent Precision Fertilizer Technology. 11th International Conference on Computer and Computing Technologies in Agriculture (CCTA), Aug 2017, Jilin, China. pp.499-506, 10.1007/978-3-030-06137-1_46 . hal-02124264

\section{HAL Id: hal-02124264 \\ https://hal.inria.fr/hal-02124264}

Submitted on 9 May 2019

HAL is a multi-disciplinary open access archive for the deposit and dissemination of scientific research documents, whether they are published or not. The documents may come from teaching and research institutions in France or abroad, or from public or private research centers.
L'archive ouverte pluridisciplinaire HAL, est destinée au dépôt et à la diffusion de documents scientifiques de niveau recherche, publiés ou non, émanant des établissements d'enseignement et de recherche français ou étrangers, des laboratoires publics ou privés. 


\title{
Research on the Current Situation and Development of Intelligent Precision Fertilizer Technology
}

\author{
Wu $\operatorname{Yan}^{1(\bowtie)}$, Wang $\operatorname{Fan}^{2}$ \\ ${ }^{1}$ Tianjin Agricultural University, Lecturer of College of Water Conservancy Engineering, Tianjin, China \\ ${ }^{2}$ Tianjin Agricultural University, Undergraduate of College of Water Conservancy Engineering, Tianjin
}

\begin{abstract}
Accurate preparation technique of water and fertilizer is the combination of irrigation and fertilization organically, and it is applied to the crop root system accurately to make the crop root system fully and directly absorb the water and fertilizer coupling solution. At present, there are mainly nutrient solution management method based on conductivity (EC) value, nutrient solution management method for nutrient addition and nutrient solution management method based on crop model. Based on the "integration of water and fertilizer" technology, precise fertilizer control technology put to use the automatic control technology, computer technology, sensor technology, etc., which can improve the accuracy of preparation of water and fertilizer solution concentration, and make the management of irrigation and fertilization intelligently, and also timing quantitative irrigation and fertilization for crop is guaranteed to improve the yield and quality.
\end{abstract}

Keywords: precision irrigation; fertilization; automatic control technology.

\section{Introduction}

China is a large agricultural country, in which the amount of water used for agricultural irrigation accounts for about $80 \%$ of the total amount of water resources in China, while the agricultural water used in $90 \% \sim 95 \%$ is mainly used for farmland irrigation ${ }^{[1]}$. In order to meet the increasing demand of grain in our country, it is necessary to increase the irrigation area and irrigation water of our country, but the shortage of water resources in our country is so serious that the development of agricultural irrigation in our country is facing a difficult situation. At the same time, fertilizer inputs account for the largest share of agricultural production. According to statistics, fertilizer generally accounted for the material input of China's grain production in $30 \% \sim 40 \%$ in the high yield region, individual or even as high as $50 \%$, the annual amount of chemical fertilizer in China accounted for the world total 1/3. However, due to the excessive use of chemical fertilizer in China, the utilization rate of chemical fertilizer is obviously low, and the average utilization rate is only $35 \%$, which is lower than that of developed countries by $10 \sim 15$ percentage points ${ }^{[2]}$. Unreasonable fertilization and irrigation caused a lot of waste of resources and pollution of farmland environment which poses a major challenge on the transformation of China's traditional agriculture to the modern agriculture upgrade. Now the solution is to research and promote the technology of precision irrigation and fertilization vigorously.

\footnotetext{
* Supported by the Open Foundation of State Key Laboratory of Hydraulic Engineering Simulation and Safety of Tianjin University (Grant No.HESS-1755) and the Scientific Research and Development Foundation of Tianjin Agricultural University (Grant No.2016NYB05) 
Precision irrigation is also called digital irrigation and prescription irrigation. Precise irrigation and fertilization technology is to make the nutrient solution into the irrigation system by fertilizing device and so that fertilizer with the irrigation water can be transported to the field. Based on the requirement of plants to water and fertilizer, automatic water and fertilizer management is carried out, which is the combination of technology of precision fertilization and precision irrigation ${ }^{[3]}$. Irrigation and fertilization technology also known as fertigation. Through the combination of water and fertilizer, and mutual promotion of the resulting interaction, the technology can effectively improve the utilization of water and fertilizer resources, saving water resources and improving the yield and quality of crops ${ }^{[4-9]}$, such as table 1 .

Table 1. Some vegetables use irrigation techniques to increase production

\begin{tabular}{lll}
\hline crop & Increase the yield(\%) & reference \\
\hline Pepper & 50 & Haynes, 1988 \\
Capsicum & 25 & Gnanamurthy and Manickasundram, 2001 \\
Chilli & 15 & Jeyabal et al., 2000 \\
French beans & 28 & Jeyabal et al., 2000 \\
Potato & 22.6 & Patel and Patel, 2001 \\
Tomato & 33.2 & S.S Hebbar et al., 2004 \\
\hline
\end{tabular}

The irrigation and fertilizing technology can reduce the labor intensity by accurately controlling the amount of irrigation and fertilizing time, and realize water saving, fertilizer saving, and medicine saving. At the same time it plays an important role in promoting the cost reduction and efficiency improvement of agriculture, and it is more and more widely used in modern agricultural production ${ }^{[10-13]}$.

\section{Present situation of precision irrigation and fertilization system}

Precision irrigation and fertilization system is divided into 4 parts: information collection system, intelligent control system, irrigation and fertilizer decision support system and remote monitoring system with fault diagnosis ${ }^{[14]}$.

\subsection{Information collection system}

The information collection system is mainly composed of the two parts: growth environment and physiological information of the plant. The growth environment information includes temperature, humidity, light and other environmental factors information, electrical conductivity, $\mathrm{pH}$, dissolved oxygen and nutrient solution composition. The collection of physiological information of the plant is the use of modern high-tech means of detection, by detecting the morphological or physiological changes of the 
leaves, stems, fruit and other crops, which can be more direct, fast and sensitive to reflect the plant moisture and nutritional deficiencies, so as to provide more scientific basis for reasonable irrigation and fertilization ${ }^{[15]}$.

\subsection{Intelligent control system}

The intelligent control system includes facilities environment control subsystem, irrigation control subsystem and nutrient liquid control subsystem. According to the requirements of different plants on the growth environment, by controlling the wet curtain fan system, heating system, shading system, supplementary lighting system and other institutions, the facilities can be controlled to the ideal environment for plant growth. The irrigation control subsystem is based on the water requirement of the plant, and uses the drip irrigation technique to realize the real-time precision irrigation. The nutrient solution control system include fertilizer system, nutrient delivery system, wherein the fertilizer system mainly includes the mother liquor tank and venturi absorbing fertilizer apparatus, mixing tank, solenoid valve and mixed fertilizer pipeline. The nutrient delivery system opens or closes the solenoid valve according to the requirements of the control area.

\subsection{Decision support system}

In the decision support system of irrigation and fertilization, a plant growth model is established, based on the technology of application data warehouse and on-line analytical processing technology, combining expert system and data mining technology to make decision for agricultural irrigation and fertilization, and further improve the accuracy of decision-making, and scientific and intelligent levels ${ }^{[16]}$.

\subsection{Remote monitoring system}

Remote monitoring system with fault diagnosis can realize on-line monitoring of irrigation and fertilization system by using internet technology, so as to improve the intelligent level of facilities and achieve the purpose of saving manpower and material resources. At the same time, the system has remote fault diagnosis function, which can monitor the fault phenomenon online and upload the fault phenomenon to the command system, so as to quickly solve the fault and improve the operation level of the system with trouble-free.

\section{Technical progress of precision irrigation and fertilization system}

\subsection{Research progress of information collection system}

Rapid detection of crop growth information is one of the key technologies in modern precision agriculture. Only by accurately obtaining the information of plant growth and understanding the situation of crop growth and nutrient deficiency in a timely manner can we realize the precise regulation of water and fertilizer.

Using spectral analysis technique to measure crop nitrogen content, it was found that nitrogen content in maize and wheat could be better detected by spectrum technique. In the field of plant nutrient sensors, there are many researches on static detection and sensing instruments both at home and abroad, and the research and application of dynamic detection and sensing instruments in agricultural internet technology are rela 
tively few. Nie Pengcheng studied the rapid nondestructive sensing technology of plant nutrients based on the technology of visible and near infrared spectroscopy, and proposed a method for the determination of plant nutrient based on the technology of visible and near infrared spectroscopy. The real-time dynamic plant nutrient and physiological information detection sensor was developed, combined with networking system and the automation control technology in agricultural, also the managements of automatic fertilizer and water are researched. For spectral analysis technology, generally the prediction performance of the model is judged by the pretreatment of spectral data, which is to find the correlation coefficient and the mean square error between the measured value and the predicted value of the sample set. The larger the correlation coefficient of the model is, and the smaller the mean square error is, and the better the prediction ability of the model.

Based on the spectral characteristics of plant nutrient, plant canopy information and plant physiological information, and according to the model built by experimental data, the detection characteristics of the band of the plant nutrient information and physiological information are founded, which can provide basis for the development of realtime dynamic plant nutrient and physiological information detection sensor ${ }^{[17]}$ for agricultural networking.

The nondestructive testing technology of crop growth information, based on machine vision, is realized by real-time monitoring of crop growth by installing cameras in planting area. It includes image acquisition, image processing, data processing, expert database (crop image database and crop growth expert database), environmental information, data output, the implementation of institutions and so on.

The use of spectral analysis technology and machine vision technology based on crop growth information detection has its unique advantages, but there are also some problems, there are high equipment investment, long development cycle, lack of detection accuracy, spectral analysis technology and machine vision technology based on the analysis of sampling plant parts, and sampling growth time to be further in-depth study, thereby improving accuracy.

\subsection{Advances in management techniques of nutrient solution}

Nutrient solution is the solution made by dissolving a variety of nutrient elements, which is necessary for plant growth and development, into water in a certain amount and proportion ${ }^{[18]}$. The growth rate and quality of the crop depends largely on the nutrient content and concentration of the nutrient solution, and whether the nutrient solution management can meet the requirements of the different growth stages of the crop. Therefore, the preparation and use of the nutrient solution in the adjustment process is the core of precision irrigation and fertilization system ${ }^{[19]}$.

Nutrient management mainly refers to the management of nutrient solution used in the process of crop cultivation. In the process of crop growth, the crop roots continue to absorb moisture, nutrients and oxygen from the nutrient solution, so that the nutrient solution concentration, composition, $\mathrm{pH}$ value, dissolved oxygen and others are constantly changing, in addition to the external environment changes also affect the temperature of the nutrient solution. Therefore, it is necessary to detect and control the nutrient solution to meet the needs of crop growth. At present, the management of nutrient solution is mainly to detect the EC value and $\mathrm{pH}$ value of nutrient solution, and the nutrient composition of nutrient solution can not be monitored online in real time. Because of the selective absorption of ions in the process of crop growth, the nutrients 
of the nutrient solution will lose the balance after a period of growth. Although the EC measurement value is within the set range, and the requirements of the preset are satisfied, the liquid nitrogen, phosphorus, potassium and other nutrient ratio was broken, resulting in plant growth and nutritional deficiencies, thus affecting the normal growth of plants. Therefore, it is necessary to strengthen the research on online monitoring of nutrient liquid components in the future, and to develop the prosthetic technology of nutrient solution to ensure that nutrient solution is balanced and reasonable.

\subsection{Research progress of decision support system}

Decision support system is the core component of precision irrigation and fertilization. It is the basis of precision and digital management of irrigation and fertilization. It is a new technology developed with the combination of artificial intelligence technology and agricultural characteristics. The use of artificial intelligence technology, a lot of valuable experience of agricultural experts and long-term accumulation of various data obtained through test data and mathematical model of knowledge, can effectively improve the decision-making capacity of managers to improve the scientific and informative decision-making degree.

The precision irrigation and fertilization decision support system should study the quantitative relationship between different stages of growth and development of crops, soil, weather and management measures, so as to provide theoretical basis for generating variable prescription at different scales. The key problem is the determination of the amount of fertilizer, and the difficulty lies in the formulation of the decision model. Pokrajac ${ }^{[20]}$ et al. give a neural network based decision support system for providing accurate fertilization decisions. Teng Qingfang ${ }^{[21]}$ et al. established the soil fertilization model using neural network. Lan Weijuan ${ }^{[22]}$ et al. applied radial basis function network to the decision of variable fertilization.

In the study of decision making system for precise irrigation and fertilization, the research of crop growth model and information monitoring about water and fertilizer would be strengthened, considering the influence of soil, crops, weather and other environmental factors, and also the research and development of the forecast decision and intelligent control decision for crop irrigation would be carried out. In particular, the fuzzy and artificial neural network techniques can be used to improve the reliability and versatility of irrigation and fertilization decision-making system, especially for the complex, fuzzy and highly nonlinear problems of irrigation and fertilization system.

\section{The prospects of research}

As the state of the environment and water resources protection attention and investment increase, precision irrigation and fertilization technology in China is subject to unprecedented attention, and its emergence of agricultural production has produced a huge role. The study of following aspects should also be strengthened in the future.

\subsection{Research on biological information sensing technology}

There are some research should be developed deeply such as the research on crop physiology, the study of the relationship between crop growth and water and nutrient elements for crop growth, the quantitative relationship between the deficiency and nutritional components, and biological information sensor, which can directly monitor the 
physiology of plant to provide original data for accurate irrigation and fertilization decision.

\subsection{Study on on-line detection of nutrient solution composition}

At present, the regulation of nutrient concentration is mainly measured by measuring the EC value and $\mathrm{pH}$ value. Although the presence of on-line monitoring technology of $\mathrm{K}+$, $\mathrm{Ca} 2+$, NO 3-, Mg2+ plasma concentration, most of the nutrient solution ions need to be analyzed artificially. Coupled with a long test time, nutrient solution supply system can not dynamically reflect the demand of a certain nutrient element and can not meet the needs of the real-time refinement management of nutrient solution. In the future, we should continue to strengthen the on-line monitoring technology of nutrient solution ions, and realize the on-line monitoring of the corresponding ions.

\subsection{Study on the model of crop for water and fertilizer}

The quantitative relationship between crop yield, water and fertilizer should be studied, and the nutrition nutrient such as nitrogen, phosphorus, potassium and irrigation on crop yield should be analyzed, and also the model of crops for water and fertilizer should be established. Only by this way, can we provide scientific basis for precision fertilization, So as to better achieve accurate irrigation and fertilization.

Acknowledgments. This project was supported by the Open Foundation of State Key Laboratory of Hydraulic Engineering Simulation and Safety of Tianjin University (Grant No.HESS-1755) and the Scientific Research and Development Foundation of Tianjin Agricultural University (Grant No. 2016NYB05).

\section{References}

1. Gao Xuemei. Development Trend and Existing Problems of Water-Saving Irrigation in Agriculture in China. J. Tianjin Agricultural Sciences. 18(01), 54-56 (2012)

2. Zhao Chunjiang. Research and Practice of Precision Agriculture. M. Beijing: Science Press, 2009.

3. Yan Chang. Irrigation Fertilization Automatic Control System. D. Wuhan: Hua Zhong Agricultural University, 2008.

4. Guo Shirong. Soilless Culture. M. Beijing: China Agriculture Press, 2011.

5. Yu Weidong, Jin Wenxin, Cao Xiaobo. Research and Application of Intelligent Water and Fertilizer Irrigation System. J. Agricultural Sciences of Jiangsu. 43(6), 415-418 (2015)

6. Gao Peng, Jian Hongzhong, WeiYang. Application Status and Development Prospects of Integrative Water and Fertilizer. J. Modern Agricultural Science and Technology. (8), 250257 (2013)

7. Zhou Bo, Zhou Jianbin. Effects of Different Fertilizers and Water Managements on Water Distribution in Soil and Water Use Efficiency of Tomato. J Northwest A \& F University(Nat. Sci. Ed.). 37(1), 211-216 (2009)

8. Chen Zhong, Zhang Yulong, DiBo. Comparison of Saving Water Effect of Tomato under Different Irrigation Methods in Solar Greenhouse. J. Irrigation and Drainage. 28(3), 105107 (2009)

9. Liu Jianying, Zhang Jianling, Zhao Hongru. Application Status, Existing Problems, Countermeasures and Development prospects of Integrative Water and Fertilizer. J. Inner Mongolia Agricultural Science and Technology. (6), 32-33 (2006)

10. Yuan Hongbo, Wang Haihua, Pang Shujie. Design and Experiment of Closed Culture System for Solar Greenhouse. J. Transactions of the Chinese Society of Agricultural Engineering. 29(21), 159-165 (2013)

11. Liu Xiuzhen, Zheng Decong, MaJun. Accurate to Irrigate and Apply Fertilizer Automatic Reseach of Administrative System and Realize. J. Soil and Water Conservation. (5), 197200 (2006)

12. Xiao Shijiang, Wu Qiongfen, Liang Shumin, et al. Study on Fertigation Technology of Winter Potato. J. Water Saving Irrigation. (1), 67-72 (2018)

13. Shi Zhigang, Liu Qunchang, Bai Meijian, et al. Water and Fertilization Integrated Intelli- 
gent Irrigation System Design and Benefit Analysis based on the Internet of Things. J. Water Resources and Water Engineering. 28(3), 221-227 (2017)

14. Liu Yonghua, Yu Weidong, Shen Mingxia, et al. Present Situation and Prospect of Intelligent Precision Irrigation Fertilization Technology. J. Jiangsu agricultural science. 42(8), 384-387 (2014)

15. Wu Delin, Mao Hanping. Greenhouse Crop Water Information Index and Humidity Control Strategy. J. China Rural Water Conservancy and Hydroelectric Power. (1), 35-40 (2007)

16. Yao Xia, Liu Xiaojun, Wang Wei, et al. The Best Normalized Spectral Index for Estimating Nitrogen Accumulation in Wheat Leaves Based on reduced sampling method. J. Applied Ecology. 21(12), 3175-3182 (2010)

17. Zhang Xiaowen, Su Boping, Sun Shubin, et al. Research and Development of Precision Irrigation Monitoring System for Facility Agriculture. J. Chinese Agricultural Mechanization. (1), 30-32 (2005)

18. Li Shijun, Guo Shirong. Facility Horticulture. M. Beijing: China Agriculture Press, 2002.

19. Ni Jiheng, Mao Hanping, Ma Wanzheng. Research Progress of nutrient solution management strategy. J. Vegetables. (6), 45-47 (2011)

20. Pokrajac D, Obradovic Z.A. Neural method Network based Forsite Specific Fertilization Recommendation. C. California USA:ASAE Annual International, Meeting, Sacramento, 2001.

21. Qin Chunlin, Teng Qing Fang, Dang Jianwu. Party Building by using neural network to establish the soil fertilization model. J. Lanzhou Railway Institute: Natural Science Edition. 21(4), 54-57 (2002)

22. Lan Weijuan, Mao Pengjun, Du Dongliang, et al. Study on Variable Fertilization Decision Making based on Radial Basis Function Networks. J. Anhui Agricultural Sciences. (21), 6505-6507 (2007) 
